\title{
Flipped learning for enhancing English pronunciation in remote teaching
}

\author{
Aprendizaje invertido para mejorar la pronunciación del inglés en la enseñanza \\ remota
}

\author{
Isaí A. Guevara-Bazán ${ }^{a}$
}

\begin{abstract}
:
The objective of this paper is to analyze, design, implement and evaluate a teaching strategy for improving specific content in remote English teaching. To do this, an approaching analysis of an eight-students A2 level group dealing with pronunciation problems was carried out. After that, an interview for collecting data about the most concurrent pronunciation problems appeared in the course. Valuable information was displayed to analyze the most common problems for pronunciation in A2 students. After interpreting the results, the pronunciation of regular verbs in the past tense was the most difficult problem for them. A specific strategy to cover students' needs was designed. Since remote teaching conveys the use of technology and flipped learning is an option for the equipment available, the implementation of a video flipped learning task was designed. With the use of technology (authoring tools and mobile Apps), flipped learning, programmed instructional design students showed improvement in the pronunciation of regular verbs in the past tense. Finally, it is concluded that this innovative strategy can effectively be reproduced for developing some other learning content in remote teaching.
\end{abstract}

Keywords:

Linguistics, language teaching, learning, flipped learning

\section{Resumen:}

El objetivo de este trabajo es analizar, revisar, implementar y evaluar una estrategia didáctica para mejorar el aprendizaje de contenidos específicos en la enseñanza remota del inglés. Para ello, se llevó a cabo un análisis de un grupo de ocho alumnos de nivel A2 con problemas de pronunciación. Posteriormente, se realizó una entrevista para recopilar datos sobre los problemas de aprendizaje que tenían los alumnos para enfrentar el curso de inglés. Los resultados del análisis mostraron que el problema más recurrente en estos estudiantes de nivel A2 era el de la pronunciación, siendo el más problemático para ellos la pronunciación de los verbos regulares en tiempo pasado. Se diseñó una estrategia específica para cubrir las necesidades de los estudiantes. Dado que la enseñanza remota a través del uso de la tecnología y el aprendizaje invertido es una opción viable para las capacidades del equipo disponible de los alumnos, se diseñó una implementación de una tarea de aprendizaje invertido por video. Con el uso de tecnología (herramientas de autoría y aplicaciones móviles), aprendizaje invertido y el diseño instruccional programado se logró que los estudiantes mostraran una mejora en la pronunciación de los verbos regulares en tiempo pasado. Finalmente, se concluye que esta estrategia innovadora puede reproducirse efectivamente para desarrollar algún otro contenido de aprendizaje en la enseñanza a distancia.

Palabras clave: Lingüística, enseñanza de idiomas, aprendizaje, aprendizaje invertido

\section{INTRODUCTION}

Remote English teaching is now considered to be one of the most necessary modalities for education since the COVID-19 pandemic forced educators to get through the use of ICT for implementing and delivering online courses. Mohite mentioned that "Due to this lockdown, all schools, colleges get closed and teaching-learning process stopped. But ICT tools come to help teachers and students. Online classes get started and once again education system gets booster."(2020, p. 18) ICT tools are used

\footnotetext{
${ }^{a}$ Isaí Alí Guevara-Bazán, Isaí Alí Guevara-Bazán, México, https://orcid.org/0000-0002-1500-291X, Email: iguevara@uv.mx
} 
for transferring competencies with synchronous and asynchronous teaching and learning tools. However, the use of ICT for developing learning requires specific analysis, evaluation, and understanding of the learning tools available for teachers and learners since, digital implementation "[s]uccess is often evaluated on the basis of adoption rather than pedagogic viability and the educational benefits"(Blandin, 2011, p. 136). To be effective, a previous analysis of the students' learning needs and the technical teacher's capabilities for using the authoring tool is necessary. Students at the A2 level were interviewed to inquire about the most important problems encountered during the learning process. The teacher requires a first analysis of the learners at the beginning of the course to identify the learning strength and weaknesses of the contents that are to be recycled and reviewed more deeply. Hence, an analysis of the contents to be checked in the course was done. The difference of this action from the typical diagnostic exam is the value of student's perceptions because they are free to express what they need and why they require some specific topics rather than the ones taken for granted in the diagnostic exam. They noticed that pronunciation of the regular verbs in the past tense was the main challenge for the course, which demands a non-stoppable remote synchronous teaching since teachers must cover the total content of the course. Gilakjani (2016) quoted Shahzada (2012) who affirmed that

“EFL teachers should be aware of their learners' needs and problems in pronunciation. Based on their needs, teachers should present some appropriate materials to their learners to reduce their learners' pronunciation problems" (p. 4).

After the specific topic is defined, the following process is to determine the strategies for enhancing learning and saving the same time for covering the contents with remote teaching. Additionally, the intention of the teacher is focused on developing autonomy with the use of ICT. The selfdetermination theory "posits that students need to learn in an environment that supports the growth of their basic psychological needs for autonomy, competence, and relatedness, which enable them to see values in their learning, and continue to learn on their own"(Poynter \& Nolan, 2014, p. 78). That is to say, there are many resources available on the internet, but not all of them are suitable for specific contents of the course syllable and for developing autonomy in students. Thus, the strategy to follow is to recover the flipped learning model with applicable individual instruction with the use of video. Flipped learning is a very effective model that consists of "the time spent explaining the subject, for example through the master class, is relegated to the work that the student can do quietly at home through recordings on a video or in a presentation narrated in PowerPoint, Prezi or a similar authoring tool"(Salcido et al., p. 111). The first step was to analyze the required contents for learning reinforcement. After that, a strategy based on the flipped learning technique was designed to cover the learning needs of the students. The main problem for this group was the pronunciation of the regular verbs in the past tense. After implementing the flipped learning strategy, students showed a significant advancement in the pronunciation of these verbs in past tense and the self-confidence for talking about past events.

\section{RATIONALE}

Throughout my remote teaching performance, I have noticed students' concern when they start a course with some previous knowledge that has not been consolidated to be linked with the scaffolding. Vandergrift \& Goh (2012) mentioned that

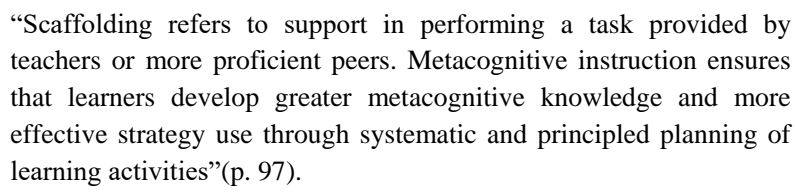
teachers or more proficient peers. Metacognitive instruction ensures that learners develop greater metacognitive knowledge and more effective strategy use through systematic and principled planning of learning activities"(p. 97).

Furthermore, some contents are quite difficult to assimilate for the learners, and sometimes the teaching process conveys special teaching procedures that demand to be redundant, repeat and cover the topic thoroughly. There are many resources available on Internet, however, not all of them are suitable for the student's level and content. For those cases, it is necessary to create a special instructional design that allows students to learn according to their learning requirements and time. Moreover, remote teaching reduces the time for synchronous interaction, since the possibility of teacher-student(s) interaction is affected using technical issues occurring in this process, such as students' equipment capabilities, time-consuming for the electronic and digital tools, the width band, the lack of appropriate spaces for showing their cameras due to different issues involved and so forth. However, it is necessary to create opportunities to learn with synchronous and asynchronous interaction because teaching flexibility during this modality is a priority for the transformation of education for the long learning and the policy of the educational system in favor of innovative and varied learning delivery.

\section{METHODOLOGY}

This was a study case research that analyzed individuals' needs on some specific content for A2 students. The question for this research was: How can pronunciation of the regular verbs in past tense be improved with the use of ICT? The process for the research was set as follows:

Analysis of students' learning requirements. An analysis of the contents, the group, the level of the students, and the needs they had for the course was done.

Designing the task. After the results of the analysis were collected, a strategy for improving the learning (pronunciation of the regular verbs in past tense) was designed to implement during the course.

Implementing the task. The implementation involved the use of a flipped learning material based on a tutorial video upload on YouTube with all the technical and academic requirements. 
Describing the results and findings. All the results and findings were described according to a checklist and a questionnaire to collect students' perceptions of their advancement in the use of past tense for expressing past events, specifically on the pronunciation of regular verbs in the past tense.

Discussion section. All the results and findings were summarized, interpreted. The implications of the study were displayed. Limitations of the study were explained, and recommendations and proposals were given.

\section{RESEARCH OBJECTIVES.}

To improve the pronunciation of the regular verbs in the past tense.

To improve students' learning with the use of ICT and flipped learning

\section{ANALYSIS OF THE CONTENT AND LEARNING PROBLEMS}

A special strategy to inquire about students' needs is to give learners the chance to express their strengths and weakness, communicate their frustrations and problems during the learning process. Hence, an analysis of the problem and learning situation was done. To do this the syllabus was revised. The group covered a total of nine participants who were purposely selected because the problems encountered had been appearing in the last courses at the same level. After that, an unstructured interview was designed. The interview was conducted with the nine participants in the group. All of them were adults who had an A2 level, and they were enrolled in the English Language level course called Intermediate 100. Nevertheless, the real level of the students according to the book they covered after the previous course was A2 (Traveler B1 based on the CEFR). The analysis of students learning needs gives teachers an overview to set teaching strategies. After the interview, they mentioned that the past tense was the most difficult issue they had to face. P4 said, "What I need is to review the past tense. I don't know the way ... the pronunciation of the past tense ... regular verbs... in the previous course I [couldn't] understand the pronunciation of it...". A second opinion about this issue confirms the need for practicing it. "... because I don't know why the -ed sound changes" (P6). They also said that irregular verbs are difficult, but they can learn the pronunciation by heart, but they would like to have a guideline to pronounce the regular verbs in the past because they said that they heard different sounds at the end. The problem seemed not to be the meaning and the context in which the past tense is used, but there must be confusion in the three segmental sounds grouped for the regular past tense pronunciation -ed [d], [t], and [Id]. Students were asked about this grouping and most of the participants mentioned that they did not have any idea about those three sounds. There was a strong tendency that showed that participants perceived a hurried instruction that did not allow them the assimilation of all the contents. "I didn't like that the teacher gave the class very rapidly. I couldn't understand some things" (P1). It may be inferred that students needed some previous or subsequent practice to let them learn the topics that involved deeper attention and engagement at their own pace. Gilakjani affirmed that "[p]ronunciation instruction is very important because it is the main source of understanding. If learners cannot utter the correct version of a word then they are not able to communicate correctly"(2016, p. 5). In addition to this, the recycling knowledge that is not assimilated would not be performed properly in upper levels when integrating language situations are accomplished. For example, when students are doing productive skills, such as speaking and writing. Henceforth, weaknesses in the pronunciation of the regular verbs in the past tense may affect the self-confidence for speaking about past events. One learner expressed that "I sometimes feel nervous when my pronunciation is not good. I sometimes don't speak because I feel terrible... I feel ... nervous of making mistakes..." (P4). The improvement of pronunciation may lead to an improvement in self-confidence when speaking.

\section{TASK INSTRUCTIONAL DESIGN}

This section describes the process to follow to create the appropriate learning process to learn the pronunciation of the regular verbs in the past tense to enhance learning and support remote teaching.

The main topic was past tense and according to the analysis done, students needed supporting on the pronunciation of regular verbs in the past tense while the remote teaching is done. It is believed that "[p]ronunciation is taught by intuition and imitation. Students mimic a model teacher and do their best to be close to the model by imitation and repetition"(Pourhossein, 2017, pp. 1250-1251). The instruction pretended to allow students to review the topic individually with some unique fragments to understand the pronunciation of the regular verbs in the past tense. McDonough, et al stated that "pronunciation and vocabulary, for instance, can both be practiced in a context of use, or alternatively can be rehearsed in isolation"(2013, p. 39). "They can also do mini-rehearsals, which will build up their confidence and improve the end result."(Sara, 2009, p. 34) for speaking. Thus, the video permits the teacher to show the patterns and model the segmental sounds for the learners. To select the most appropriate authoring tool for developing the learning environment an evaluation of the different tools available was done. As a teacher, we must think on the most feasible tool to enhance learning. Karoulis \& Pombortsis stated that "usability and learnability are correlated terms and that the usability of the educational environment affects its learnability in a positive way"(Blandin, 2011, p. 93). The use of video includes the practical process to publish it on demand and creates a possibility to share it on multi-platforms for almost all kinds of devices. For 
developing the video, the PowerPoint software allows designers to produce videos with interactive animation. This video is planned and designed according to the general instructional standards. It is planned to be implemented before the synchronous class. Hereafter, the most convenient model for the intervention was flipped learning, which is a blended learning process that has students interact with the learning material previously to the synchronous interaction, so that students may confirm, ask, and get a deeper understanding of the topic with the teacher-student(s) interaction. The task can be implemented with different learning tools. The most appropriate seemed to be the video, which allows students to revised and check the material with a high level of independent manipulation. At the same time, it provides the teacher the opportunity to explain the topic in detail. The process to develop the video is very accurate and implies planning and time-consuming. However, the result is worthwhile since it is a very suitable and effective instructional tool for adding sounds, text, and movement, as well as a proper storyboard to develop the topic. The authoring tool selected was PowerPoint, which allows the designer to create videos with high quality. After the rough video is finished the editing process was done with Avidemux, an open-source tool for editing video.

The script has the following structure: a) Introduction to the sounds for the regular past tense pronunciation -ed [d], [t], and [Id]. 2) Why does the sound of the ending-ed change? 3) The three groups of the sound -ed, 4) First group: Voiced sounds before the ending -ed [d], 5) Second group: Voiceless sounds before the ending -ed [t], 6) Third group: Sounds /t/ and /d/ before the ending -ed [Id] (See figure 1).

\begin{tabular}{|l|} 
There are three groups of the sound -ed \\
First group: Voiced sounds before the ending -ed $\begin{array}{r}{[\mathrm{d}]} \\
\text { played } \\
\text { [d] }\end{array}$ \\
Second group: Voiceless sounds before the ending -ed $[\mathrm{t}]$ \\
worked \\
[t] \\
Third group: Sounds / $\mathrm{t} /$ and /d/ before the ending -ed [Id] \\
visited \\
{$[\mathrm{ld}]$}
\end{tabular}

Figure 1. The three groups of the sound-ed.

The most important teaching intention is to enhance recognition of the voiced and voiceless sounds since those crucial segmental sounds define the way the first two groups -ed [d] and ed [t] are pronounced (See figure 2).

\section{First group: After voiced sounds [d] \\ VIBRATION in your throat \\ Second group: After Voiceless sounds NO VIBRATION in your throat
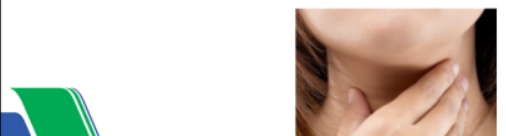

Figure 2. The two groups of the sound-ed: voiced and voiceless sounds.

The instruction explained all the sounds that correspond to the first and second groups in detail, including the vowels, which are all voiced sounds (See figure 3 ).

\begin{tabular}{|c|c|c|}
\hline Voiced sounds & Voiceless & ounds / $t /$ \\
\hline [b] [z] & [p] & [s] \\
\hline [g] [3] & {$[\mathrm{k}]$} & [s] \\
\hline$[ð] \quad[d z]$ & {$[\theta]$} & {$[\mathrm{t}]$} \\
\hline$[\mathrm{v}] \quad[\mathrm{m}] \quad[$ & [f] & \\
\hline
\end{tabular}

Figure 3. The two groups of the sound-ed: the total sounds with voiced (including vowels) and voiceless sounds.

Finally, the category with the verbs ending $-t$ or $-d$ is a more feasible group to be explained. At the end of the sections, the pronunciation of some examples for each group was displayed.

\begin{tabular}{|c|c|c|c|}
\hline \multicolumn{4}{|c|}{ verbs ending -t or -d EXAMPLES } \\
\hline $\begin{array}{l}\text {-accepted } \\
\text { - arrested } \\
\text { •collected } \\
\text { •counted } \\
\text { •decided } \\
\text { •visited } \\
\text { •waited } \\
\text { •wanted } \\
\text { •wasted }\end{array}$ & $\begin{array}{l}\text {-demanded } \\
\text {-divided } \\
\text { - ended } \\
\text { - expanded } \\
\text { - expected } \\
\text { - exported } \\
\text { - flooded } \\
\text {-graduated } \\
\text { - started }\end{array}$ & $\begin{array}{l}\text {-hated } \\
\text { - hunted } \\
\text { • included } \\
\text { - invented } \\
\text { - invited } \\
\text {-landed } \\
\text {-needed } \\
\text {-painted } \\
\text {-respected } \\
\text { - rested }\end{array}$ & $\begin{array}{l}\text {-planted } \\
\text {-presented } \\
\text {-pretended } \\
\text {-printed } \\
\text {-protected } \\
\text {-provided } \\
\text { - rented } \\
\text {-repeated } \\
\text { - reported }\end{array}$ \\
\hline
\end{tabular}

Figure 4. The third group of the sound-ed, and examples.

The final process for this video was to upload it on YouTube. This platform was chosen because it provides metadata, tags, description of the video, social network interaction, and practical ways to see and deliver the video such as accessing the link, embedded code, insertion possibilities as SCORM ("Sharable Content Object Reference Model"). The access for the video for the flipped learning implementation is here: Pronunciation of regular verbs in the past tense - YouTube. The implementation of it is planned to be done before the class for asking students to revise and check the video. They were also asked to write a 
conclusion about the three segmental sounds that occurred when the regular verbs in the past tense are pronounced. It's supposed that all students may bring their conclusions to the class and share their thoughts in a collaborative group activity. After that, teacher-student(s) interaction is done to clarify the point and explain the content comprehensively.

\section{INTERVENTION}

There must be a previous technical preparation and checklist for implementing the intervention. The video on YouTube was tested and revised. The pre-activity was written and posted on the educational platform. The video was embedded below the written instructions in the learning management system. The instructional design for the task was revised to check the clarity of instructions. All the equipment for the videoconferencing was tested before the synchronous interaction. Before doing the intervention the possibilities for a pre-and post-implementation were analyzed. Some students could be absent when the task was provided and requested. Consequently, there should be two intentional teaching strategies for using the video. The first one was accomplished by asking them to do the learning task before the class started. The second moment was carried out when some students did not attend the class. Hence, they were asked to do the learning task for reinforcing the content.

\section{Evaluation of the intervention}

The evaluation of the intervention included an evaluation questionnaire for the learners with a Likert scale of 1-5. The criteria to evaluate the implementation included the following statements. All of them were ranged from 1 to 5. 1) Completely disagree, 2) Disagree, 3) Undecided, 4) Agree, and 5) Strongly agree.

1) The flipped learning task for improving your pronunciation of regular verbs in the past tense was effective enough in giving instructions, exposition structure, clarity, and explanation.

2) The technical capabilities to do the flipped learning task for improving your pronunciation of the regular verbs in past tense were viable and practical for you.

3) The flipped learning task for improving your pronunciation of regular verbs in the past tense provided feasible learning opportunities for improving your pronunciation of the regular verbs in the past tense.

4) The flipped learning task covered my specific learning needs for improving the pronunciation of the regular verbs in the past tense.

5) The instructions for the teacher in the synchronous class were appropriate to accomplish the learning goals and the flipped learning task for improving pronunciation.

The second part of the intervention evaluation took place during the class. They were asked to give their opinion about this implementation.

How did you feel with the task?

What did you learn about the pronunciation of the regular verbs in the past tense?

What things would you suggest for improving this learning task?

\section{RESULTS AND FINDING}

The most important fact when doing a study case research is the valuable learning information collected from the teaching performance. Further, it provides teaching enhancement in real practice, and we also have a deeper understanding of the teaching or learning problem. Solutions for improving learning can vary, but the more individually we analyze the learning situation, the wiser the decisions from the teacher are in concordance with the real needs of the students. Most all the results showed a significant and constant tendency on the individuals to believe that the flipped learning implementation was a suitable strategy to help students increase their English knowledge. The intervention was evaluated to improve the learning instructional design. How did the intervention work for the students? As can be seen in figure 1 , results showed that students perceived the task instructions were clear enough to be done.

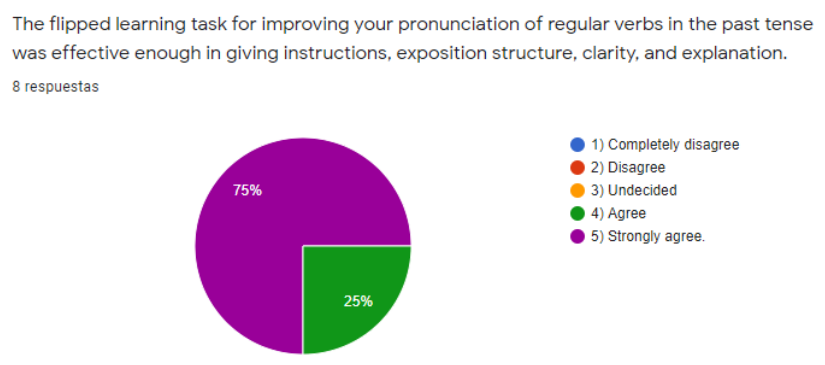

Figure 5. Students' perception of the flipped learning instruction.

However, there is a low tendency that expressed non-total agreement. Consequently, teachers' instructional design must be reviewed to ensure learners have no tackles to carry out the task.

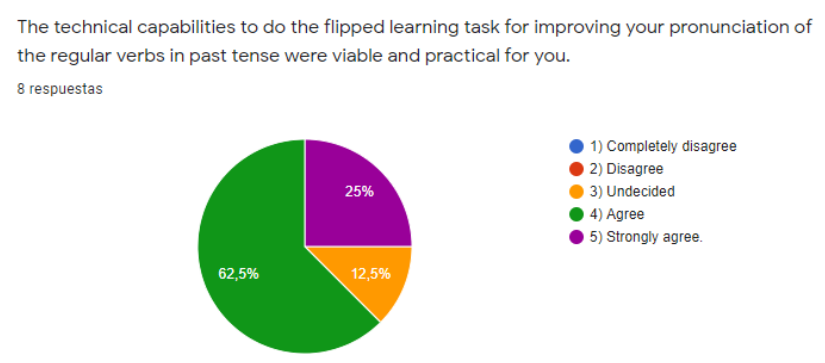

Figure 6. Students' perception of the technical capabilities.

In figure No. 2 they expressed less agreement on the capability issues. I asked them to inquire about it and they expressed that the video was easy to use, but the problem was the jargon used for phonetic symbols and linguistic issues. They overcome the 
meaning of the symbols by using some resources on Internet, but it was really difficult for them to understand it. Consequently, the problem was not a technical one, but the terminology used for the explanation of the topic. It is concluded that less terminology must be used to explain the contents to the students.

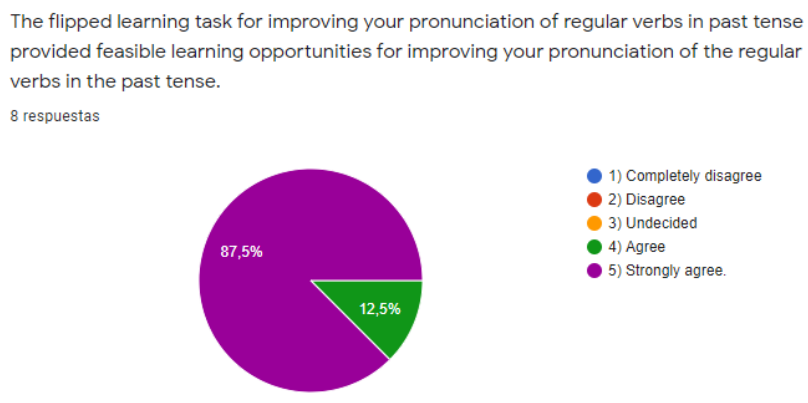

Figure 7. Students' perception of the flipped learning task feasibility.

Figure No. 3 demonstrated that students agreed that opportunities to learn about pronunciation were given. Even though almost the total agreement is obtained, a thorough review of the expanding learning possibilities is to be done.

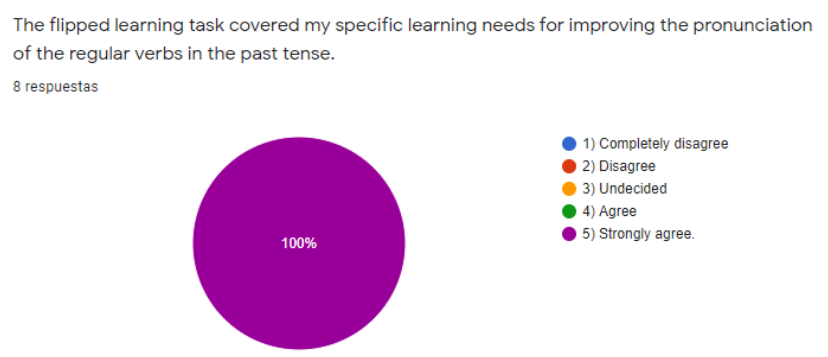

Figure 8. Students' perception of the appropriately covered learning needs.

As it can be observed in Figure No. 4, students agreed on the statement that the content was covered, and the learning needs of the students were included. In figure No. 5, learners express the total agreement for the synchronous instruction. This stage included a detailed explanation of how to use the video and the instructions to follow to take advantage of the video.

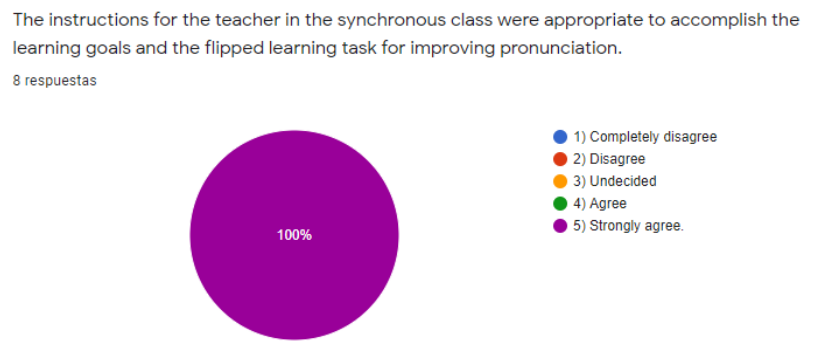

Figure 9. Students' perception of the teacher's synchronous instruction for the learning task.
How did the intervention work for the teacher? To be objective is the best option to increase the teacher's performance. The first thing to notice is the low level of competence in writing the script for the video. It seemed to be easy, but it was not because it required planning, the use of a storyboard to make planning more effective, the competence to use the authoring tool (PPT with video). Students answered the evaluations questions in class in a short time. They expressed satisfaction with the learning instruction and remark on the importance of interactivity since they said that interactivity after or during the video is needed. The length of the video was not appropriate for the two participants because they have little time to check videos. A shorter video is recommended by those participants. Two more participants agreed that the group activity in the synchronous class was very rewarding and meaningful because they could share and consolidate their acquired knowledge. Self-awareness was not mentioned to me, but it was noticed that most of the participants developed it in the learning task, since interventions in the oral activity for discussion they expressed that they got surprised about the capabilities they had to learn in isolation.

We must conclude that there must be more training for editing videos since editing was difficult and time-consuming due to the use of a new open-source digital tool, which was unknown for the editor. The self-learning was also applicable for the teacher who needed to reach the learning curve to use PPT with video, storyboard to keep a lineal sequence, editing video. The possibilities of the video for flipped learning are endless. It is suitable for supporting remote teaching and face-to-face classes. It is practical to use with all kinds of students and provides consolidating learning practice. It is also a recycled material that can eventually be used for individual content learning reinforcement. Additionally, the main characteristic of this learning model is the specific intention to enhance learning and focus the attention on students learning needs. However, the process for instructional design and video development is very slow, thus, the teacher requires time, training, and the appropriate use of ICT for creating innovative learning environments.

The use of flipped learning created an opportunity to develop linguistic topics with the use of ICT. All the learning instructions covered the pronunciation issues for enhancing pronunciation. It can be observed (during the speaking practice) that most of the students improve their pronunciation of the segmental features for the regular past tense pronunciation -ed [d], [t], and [Id] -a mistake that was fossilized This improvement affected positively the speaking skill because learners feel confident when they dominate the appropriate pronunciation for specific oral situations, such as the use of past tense to talk about past events.

\section{DISCUSSION}

Enhancing learning for remote teaching is challenging due to the lack of time and the difficult conditions the student is receiving the English instruction. Most of the students and teachers are not trained for remote learning and the spaces and equipment are 
usually not appropriate for getting adapted to synchronous and asynchronous learning. "The tasks of educational institutions needed to start being performed in a different form, which no teachers or learners were prepared for, i.e., through remote education and online teaching"(Marchlik et al., 2021). Teachers' instruction should be well planned and cover the contents with specific strategies that allow students to be integrated with the learning activities. To do so, appropriate implementations must be in concordance with the equipment, gadgets, and technical capabilities available. On the other hand, asynchronous interaction, as well as learning processes played an important role in remote teaching, since those are the key point to support contents that must be reviewed and consolidated. The flipped learning might be the correct choice for delivering instructional-designed learning tasks to prepare the students for dynamic synchronous instruction. In this model, the teacher gives instructions to the students that this teaching practice is focused on students' needs. Students are the main characters of the teaching process, and they are responsible for the construction of learning, expressing their ideas, opinions, doubts, and actions that allow them to develop critical thinking. Further, the flipped learning task may be a consolidating material to revise the contents and clarify questions about the contents. Flipped learning is a very relevant model that can be implemented in remote teaching with the use of appropriate animated and interactive ICT material, such as videos, PPT, and animated flashcards. The indirect instruction for self-learning is promoted, as well as a detailed structure that provides feasible and flexible information available at all times. The most valuable issue is the specific focus on the students' needs and the course contents. That is, there may be many resources available on Internet, but not all of them are suitable for the specific contents of your course. Moreover, designing, developing, and editing the flipped learning material conveys planning, and consistency, which yields more quality in the instruction. Additionally, (Chen \& Zhao, 2017)

\footnotetext{
"learners are in a state of non-continuous learning, so it is difficult to complete one time if the learning content includes more knowledge. Therefore, learning content is divided into a minimal knowledge block according to the actual situation of granularity of learning content which" (p. 266)
}

One of the unanticipated findings is the unexpected training needed for this task learning development. The use of ICT includes evaluating the authoring tools available, pass the learning curve for using the digital tool, and developing a storyboard for the learning task. Novice instructional designers may have problems developing the material if they are not trained to combine the ICT with the pedagogical framework required. In this study, we discovered that some students are completely independent, and they enjoyed learning at their own pace. Some of them expressed that revising the topic before the synchronous class is convenient to face the instruction with the teacher.
Before concluding the discussion, it must be stated that this study is focused essentially on one specific group that have particular features; therefore, it is impossible to create fundamentals for theorization, but the case study improved teacher's performance and motivated students to use learning processes and enhance teacher's instruction techniques. Additionally, this study case is not intended to use the students' statements and tendency to generalize the behaviors and patterns, but data support the validity of the findings to interpret this remote teaching situation. As A Result, the findings and conclusions of this study are important, and they support wider knowledge or understanding of the research problem that was studied by some authors. Further research may use these results and findings for a deeper study on the learning process, the use of flipped learning for English remote teaching, and ICT for improving English learning. Linguistics and teaching language are now immersed in non-conventional modalities since the global development constrained teaching English to change the learning environments, the demanding studying situations, the use of ICT as a means for delivering education not only for long life learning but for satisfying the community, the economical demands, the education equality for all people.

\section{CONCLUSION}

As this is a specific study for a special group of individuals, this research may conclude results and findings based only on the specific characteristics of the participants, their opinion, and the specific learning situation. However, results may be helpful to observe and reflect on the relevant findings that are focused essentially on the learning process, the instructional design, and the plipped learning advantages, which can be helpful for further researchers when they observe humans' attitudes towards the use of ICT for teaching and learning.

Furthermore, it could be valuable to analyze how to face the problems of the students learning in remote teaching. It is also appropriate for further research that intends to find out the strategies used for improving learning with the use of ICT, especially with flipped learning, which can be a supporting strategy to develop linguistic contents with a consistent instructional design. Likewise, due to the pandemic, COVID-19 remote teaching requires a variety of strategies to accomplish the pitfalls that may appear when students and teachers did not expect to work online, and training was not given to any of them to manage with virtual environments. Now the requirements for English teaching are different due to the rapidly evolved technology and the aptitudes of the participants.

Thanks to precise specification of content for the ICT training, it has become possible to make the instruction uniform within the following four thematic areas: 1. using terminology, equipment, software, and methods of ICT; 2. ICT as a component of teacher's work; 3. the implementation of ICT in teaching a given subject; 4. humanistic, social, ethical, and legal aspects of access to and use of ICT(Jarosław, 2006, p. 176) 
Moreover, multiple situations have arisen, such as lack of personal equipment, lack of training, inappropriate spaces for virtual interaction, and the stress level produced by the isolation and the shut-off. It is also recommended that "a needs analysis is to be executed to investigate the priorities of teachers (after all, with mostly practitioners being well-aware of how they would like to exploit technology in everyday teaching)"(Jarosław Krajka, 2006, p. 177) The teacher requires to increase the use of the technology available for education and lower the stress when learning since putting students under pressure may affect them to learn content and functions. The key point is to make learners develop skills for self-learning, increase self-confidence, motivation to learn, and create opportunities and learning environments and material to learn and develop the English language.

Moreover, the example given in this paper is only a small example of the increasing tendency of the use of flipped learning for several subjects. Participants agreed on the feasibility of the implemented task particularly because they are in favor of detailed self-instruction, they have the chance to manipulate the video to stop, analyze and start it again at any frame. "One aspect of pronunciation activities that proves particularly beneficial to learners is the opportunity to repeat tasks over time"'(Fitzpatrick, T., et al, 2018, p. 51). They agreed on learning the topic previously to the class because they are curious about dynamic learning, and they have the technical capabilities to work with virtual learning. Nowadays, learners are using a wider repertoire of resources to improve language learning specifically the ones found on the Web, applications and social networks, and educational platforms. All of them are now trying to fit the semantic integration of all the components of modern life: economical needs, joys, music, entertainment, social interaction, contextualized human behaviors, health, selflearning systems, voice, face, image, form recognition, and so forth. Hence, teaching language study programs must be going with technology advancement. There are now many more possibilities displayed and offered on the Web, on mobile applications, and on the freelancers and companies offering English with different perspectives which are focused essentially on developing learning by drilling, exercises, quizzes, self-evaluations, and simulating situations, however, the art of solving a specific learning problem is still demanding and useful for your students. The results in this research do not try to set the teachers' synchronous instruction apart. On the contrary, it is appropriate for creating teacher-student(s) interaction, applying teaching techniques and strategies which can be applied in the synchronous online interaction. Flipped learning is an approach that supports teaching. The confusion about their purpose is sometimes what creates the misconception, fear, and the perception that it can be used individually without the teachers' instruction. "The desired results of this model is to enable students to achieve a higher level of learning and participation, to optimize the teachers' teaching hours and to expand the learning goals to areas beyond
knowledge"(Chen \& Zhao, 2017, p. 265) For instance, the analysis and design of the flipped learning implementation are based on the course needs and the learning content needs -in this case for enhancing pronunciation. This implementation may support teachers' instruction and 'consists in helping learners create accurate perceptual representations of the target features so that they can monitor their pronunciation and continue making progress autonomously"(Fouz-González, 2019, p. 151). Also, it is well known that any implementation must be revised and evaluated afterward to make the task instruction more accurate and efficient. Finally, the "research needs to continue exploring tools and techniques that are easily interpretable and accessible for any learner, as this should allow teachers to incorporate pronunciation as an integral element of their syllabi more easily"(Fouz-González, 2019). Segmental sounds are still difficult to assimilate for learners, but providing reliable, practical, and useful self-learning material can contribute to support learning progress.

\section{REFERENCES}

Blandin, B. (2011). Usability Evaluation of Online Learning Programs. In Usability Evaluation of Online Learning Programs. https://doi.org/10.4018/9781591401056.ch017

Chen, C., \& Zhao, L. (2017). Design and Research of Mobile Learning Platform from the Perspective of Flipped Classroom. 61(Emcs), 265270. https://doi.org/10.2991/emcs-17.2017.53

Fitzpatrick, T., Morris, S., Clark, T., Mitchell, R., Needs, J., Tanguay, E. and Tovey, B. (2018). Rapid Evidence Assessment: Effective Second Language Teaching Approaches and Methods.

Fouz-González, J. (2019). Podcast-based pronunciation training: Enhancing FL learners' perception and production of fossilised segmental features. $\quad \operatorname{ReCALL}, \quad 31(2), \quad 150-159$. https://doi.org/10.1017/S0958344018000174

Gilakjani, Abbas Pourhosein. (2016). English Pronunciation Instruction: A Literature Review. International Journal of Research in English Education, 1(1), 1-6. http://ijreeonline.com/article-1-21-en.html

Gilakjani, Abbas Pourhossein. (2017). English Pronunciation Instruction: Views and Recommendations | Gilakjani | Journal of Language Teaching and Research. Journal of Language Teaching and Research, 8(6), 1249-1255. 10.17507/j1tr.0806.30

Jarosław Krajka. (2006). Jarosław Krajka ICT in the Foreign Philology Curriculum - Towards a Systematic Approach to E-Teacher Training.

Manisha Mohite. (2020). Online Education Use of Apps Platforms for Online Education Use of Different E- Contents. 2(4), 17-23. https://coed.dypvp.edu.in/educational-resurgencejournal/documents/july-2020/03.pdf

Marchlik, P., Wichrowska, K., \& Zubala, E. (2021). The use of ICT by ESL teachers working with young learners during the early COVID-19 pandemic in Poland. Education and Information Technologies, 0123456789. https://doi.org/10.1007/s10639-021-10556-6

McDonough, Jo, Christopher, Shaw, Hitomi, M. (2013). MATERIALS AND METHODS IN ELT (3rd ed.). Wiley-Blackwell.

Poynter, E., \& Nolan, J. (2014). English as a global language: where to for pronunciation teaching? In Opening New Lines of Communication in Applied Linguistics: Proceedings of the 46th BAAL Annual Meeting (Issue September). http://baal.org.uk/proceedings_2013.pdf 
Salcido, R. E., Guadalupe, L., Dise, M., Toda, N., Editorial, A., \& No, H. (n.d.). Innovación tecnológica en las prácticas educativas.

Sara, K. (2009). Teaching English at Damascus University medical school. Eastern Mediterranean Health Journal, 15(3), 653-664. https://doi.org/10.26719/2009.15.3.653

Vandergrift, L., \& Goh, C. C. M. (2012). Teaching and learning second language listening: Metacognition in action. Teaching and Learning Second Language Listening: Metacognition in Action, 1-316. https://doi.org/10.4324/9780203843376 